\title{
A INFLUÊNCIA DA GESTÃO DO CONHECIMENTO NA MOTIVAÇÃO EMPREENDEDORA DE PROFISSIONAIS DA ÁREA DETECNOLOGIA DA INFORMAÇÃO
}

\author{
THE INFLUENCE OF KNOWLEDGE MANAGEMENT ON THE ENTREPRENEURIAL \\ MOTIVATION OF PROFESSIONALS FROMTHE INFORMATION TECHNOLOGY \\ INDUSTRY
}

\section{LA INFLUENCIA DE LA GESTIÓN DEL CONOCIMIENTO EN LA MOTIVACIÓN DE EMPRENDEDORES DE LATECNOLOGÍA DE LA INFORMACIÓN}

\begin{abstract}
Isabela Dias Neves* isabela_dias94@hotmail.com

Juliana Marangoni Amarante** juliana.marangoni.amarante@gmail.com

Cláudia Herrero Martins Menegassi**** claudia.menegassi@unicesumar.edu.br

* Bacharel em Administração pela Universidade Estadual de Maringá, Maringá-PR - Brasil. ** Doutora em Administração. Docente do Departamento de Administração da Universidade Estadual de Maringá, MaringáPR - Brasil.

*** Doutora em Administração. Docente do Programa de Pós Graduação em Gestão do Conhecimento nas Organizações, Centro Universitário de Maringá, Maringá-PR - Brasil e pesquisadora do Instituto Cesumar de Ciência, Tecnologia e Inovação

(ICETI), Maringá-PR - Brasil.
\end{abstract}

\section{Resumo}

No século XXI o conhecimento passou a ser considerado recurso integrante dos fatores de produção de todos os tipos de organização. Sua gestão, primeiramente de cunho funcionalista, passou a significar ganhos não somente para as organizações, mas para as pessoas que nelas trabalham. A falta dessa gestão, todavia, principalmente em empresas da área de tecnologia, pode causar descontentamento no trabalho e, inclusive, a busca por outra atividade na qual seja possível aplicar uma Gestão do Conhecimento adequada, tão necessária na área de Tecnologia da Informação. Diante desse contexto, a presente pesquisa teve como objetivo compreender a influência da Gestão do Conhecimento na motivação empreendedora de profissionais da área de Tecnologia da Informação na cidade de Maringá - PR. Os resultados demonstraram que a motivação para o empreendedorismo na área de Tecnologia da Informação por pessoas que trabalhavam previamente em empresas dessa mesma área, teve influência expressiva do descontentamento com a forma como era conduzida - ou não conduzida - a Gestão do Conhecimento nessas empresas, fazendo com que os entrevistados optassem por abrir negócios próprios na área, onde pudessem ser protagonistas dos processos típicos da Gestão do Conhecimento.

Palavras Chave: Tecnologia da Informação. Conhecimento. Empreendedorismo.

\begin{abstract}
In the context of the 2 Ist century, knowledge has become considered a resource of the production factors in all types of organization. Its management, formerly functionalist, has come to mean gains not only for organizations but for the people who work in them. The lack of such management, however, especially in technology companies, may cause dissatisfaction at work and even the search for another activity in which it is possible to apply an appropriate Knowledge Management, so much needed in the area of Information Technology. Given this context, this research aimed to comprehend the influence of Knowledge Management on the entrepreneurial motivation of professionals from the information technology industry in the city of Maringá - PR. The results showed that the motivation for entrepreneurship in the area of Information Technology by people who had previously worked in companies in the same area, had a significant influence on the discontent with the way Knowledge Management was conducted - or not conducted at all - in those companies. Therefore, the interviewees decided to leave their previous jobs at those companies to start their own business in the same area, where they could be protagonists of the typical processes of Knowledge Management.
\end{abstract}


Keywords: Information Technology. Knowledge. Entrepreneurship.

Resumen

En el contexto del siglo XXI, el conocimiento se ha convertido en un recurso de los factores de producción de todo tipo de organización. Su gestión, previamente funcionalista, ha significado ganancias no solo para las organizaciones sino también para las personas que trabajan en ellas. Sin embargo, la falta de dicha gestión, especialmente en las empresas de tecnología, puede causar descontento en el trabajo e incluso la búsqueda de otra actividad en la que sea posible aplicar una Gestión del Conocimiento adecuada, tan necesaria en el área de la Tecnología de la Información. Dado este contexto, esta investigación tuvo como objetivo comprender la influencia de la Gestión del Conocimiento en la motivación empresarial de los profesionales de la Tecnología de la Información en la ciudad de Maringá - PR. Los resultados mostraron que la motivación para el emprendimiento en el área de Tecnología de la Información por parte de personas que anteriormente trabajaban en empresas en esta área, tuvo una influencia significativa en el descontento con la forma en que se llevó a cabo la Gestión del Conocimiento, o no. Los entrevistados optaron por abrir sus propios negocios en el área, donde podrían ser protagonistas de los procesos típicos de Gestión del Conocimiento.

Palabras clave: Tecnología de la información. Conocimiento. Emprendimiento

\section{INTRODUÇÃO}

O conhecimento sempre fez parte do ambiente organizacional. Todavia, seu estudo passou a ser inserido nesse campo principalmente a partir de meados da década de 1970 a partir da obra de Peter Druker "Uma era de descontinuidade", em que o autor fala sobre a sociedade do conhecimento, a economia do conhecimento, conhecimento como fator de produção, afirmando que "o conhecimento é atualmente o custo principal, o principal investimento e o principal produto da economia avançada" (DRUCKER, 1976, p.298).

O empreendedorismo na atualidade encontra-se associado a questões relacionadas a conhecimento. De acordo com a pesquisa Global Entrepreneurship Monitor (GEM, 2016), 40 milhões de brasileiros estavam envolvidos com atividades empreendedoras e, em essência, eram motivados por duas vertentes principais: a necessidade em momentos de crise financeira ou desemprego e a oportunidade, ou seja, quando uma pessoa reconhece uma ideia de negócio que pode dar certo e investe tempo, dedicação e dinheiro para tornar o empreendimento possível. Todavia, retomando a afirmação de Drucker (1976), que cita o conhecimento como sendo o custo principal de uma organização, pode-se inferir que também a falta da gestão desse conhecimento pode resultar em problemas internos às organizações, gerando também desmotivação e custos decorrentes.

Sendo assim, além da visão clássica sobre empreendedorismo por oportunidade ou por necessidade, pode surgir ainda outra categoria motivada pelo descontentamento com o status quo e a vontade de se fazer diferente, sobretudo em termos de Gestão do Conhecimento (GC) em empresas da área de Tecnologia da Informação (TI), cuja natureza da atividade requer em seus processos uma eficiente e eficaz Gestão do Conhecimento. 
Considerando a definição de empreendedorismo e as motivações empreendedoras, é possível analisar o setor de TI e fazer uma relação do empreendedorismo com o surgimento de novas empresas de software, que muitas vezes é motivado pelo desenvolvimento de um produto inovador - intensivo em conhecimento - e faz com que esse setor da economia tenha elevada taxa de natalidade de empresas cujo foco é a inovação.

De acordo com publicação no site de notícias do Jornal Gazeta do Povo (SILVEIRA, 2018), a cidade de Maringá no Estado do Paraná, Sul do Brasil, possui 400 empresas de desenvolvimento de software e em torno de quatro mil funcionários atuando na área de TI, fazendo com que o setor da cidade fique atrás apenas de São Paulo em número de empresas com certificações de qualidade em tecnologia. A análise da trajetória empreendedora de empresas desse setor auxilia a compreensão das motivações de egressos de empresas de TI da cidade de Maringá para o empreendedorismo, tendo em vista o crescimento acentuado desse setor no município nos últimos anos.

Considerando esse contexto, a presente pesquisa tem o objetivo de compreender a influência da Gestão do Conhecimento na motivação empreendedora de profissionais da área de Tecnologia da Informação na cidade de Maringá - PR.

Na próxima seção será apresentada a revisão da literatura, contendo informações e conceitos teóricos sobre GC e empreendedorismo na área de TI. Na sequência serão apresentados os procedimentos metodológicos adotados na pesquisa e, por fim, serão apresentadas as considerações finais e as referências utilizadas.

\section{GESTÃO DO CONHECIMENTO}

O conhecimento, naturalmente, faz parte das atividades humanas desde os tempos mais remotos. Muito se conhecia empiricamente para depois se transformar em conhecimento tácito e, na sequência, conhecimento institucionalizado como 'a forma de se fazer as coisas' (BERGER; LUCKMANN, 2009).

É evidente que o conhecimento adquirido pela experiência, internalizado e que adquire status de algo taken for granted, ou seja, dado como certo (SCOTT, 1987) não era definitivo e, ao longo da história, diversos processos de crise de paradigmas e de surgimento de novos (KHUN, 2001) aconteceram e acontecem até a atualidade. Além disso, o conhecimento passou a ser elemento de estudo e observação não somente no campo da filosofia ou dos estudos cognitivos, mas também como elemento constituinte e propulsor da sociedade e da economia. 
Foi nesse sentido que a obra de Peter Drucker "Uma era de descontinuidade" (1976) se tornou seminal ao trazer a temática do conhecimento como base do desenvolvimento da sociedade, da economia e das organizações. Nessa obra o autor descreve o conhecimento como sendo o fator principal da economia, mesmo que na época esse tema não fosse trabalhado pelos economistas, e defende a necessidade de uma teoria que pudesse mensurar a efetividade do conhecimento nas empresas. Drucker estava entrevendo o que mais tarde se estruturou como Gestão do Conhecimento (Knowledge Management).

A temática da GC começou a integrar os estudos organizacionais a partir de meados da década de 1980, tomando um impulso maior na década de 1990 e sendo desenvolvida a partir de então. Inicialmente, autores como Wiig (1993), Nonaka e Takeuchi (1997; 2008) e Davenport e Prusak (2003) deram as primeiras contribuições à área, tornando-se autores seminais. A partir de então a literatura acerca da GC vem sendo desenvolvida e aprimorada, considerando seus três pilares: pessoas, processos e tecnologias (BATISTA et al 2005).

Trata-se de uma área interdisciplinar e com diversas vertentes de desenvolvimento. Sendo assim, não há nem mesmo conceitos unânimes. Embora haja essa diversidade, Dalkir (2011) afirma que a maioria dos conceitos concorre para a definição de que a GC se trata da combinação de conhecimentos tácitos e explícitos com o objetivo de adicionar valor à organização. Tarapanoff (2001, p. 312) define GC como "processos sistemáticos, articulados e intencionais, apoiados na identificação, geração, compartilhamento e aplicação do conhecimento organizacional, com objetivo de maximizar a eficiência e o retorno sobre os ativos de conhecimento da organização".

Esses processos são descritos e organizados em modelos, ciclos, práticas e ferramentas. Os modelos de GC são diversos e os mais utilizados até o momento são os desenvolvidos por Wiig (1993), Von Krogh e Roos (1995), Nonaka e Takeuchi (1997), Boisot (1998), Hansen, Nohria e Tierney (1999) e Choo (2002).

O modelo de Wiig (1993) está pautado na ideia de que a GC pode melhorar o desempenho e a sustentabilidade das organizações a partir da GC. O modelo desenvolvido por Von Krogh e Ross (1995) traz uma distinção entre o conhecimento individual e o social e pressupõe que não há conhecimento sem um conhecedor O modelo de Nonaka e Takeuchi (1997), por sua vez, tem o foco na criação do conhecimento e nos quatro modos de conversão do conhecimento envolvendo conhecimentos tácitos e explícitos: socialização, externalização, combinação e internalização. O modelo de Boisoi (1998) se fundamenta no que o autor chama de "bem informacional", que é aquilo que o observador extrairá dos dados a partir de suas expectativas ou conhecimento prévio. O modelo de Hansen, Nohria e Tierney (1999) identificou duas estratégias de GC que as empresas utilizam: a 
codificação e a personalização. Por fim, o modelo de Choo (2002), que pressupõe que a estrutura da GC seria a criação de significado, a construção de conhecimento e a tomada de decisões que, quando conectadas, embasam as atividades que fornecem à organização conhecimentos que a levam a agir de maneira inteligente.

Além dos modelos, a GC é composta por ciclos e suas atividades ou processos. Também em relação aos ciclos há diversas perspectivas, mas Evans e Ali (2013) propuseram um ciclo por eles denominado "IOSAEC KM Life Cycle" que apresenta de forma completa as atividades ou processos referentes a um ciclo de GC. A sigla IOSAEC vem das iniciais dos processos por eles descritos: identify (identificar), organize and store (organizar e armazenar), share (compartilhar), apply (aplicar), evaluate and learn (avaliar e aprender) e create (criar).

O início do ciclo é marcado pelo processo de identificar os ativos de conhecimento, para posteriormente gerenciá-los. Nessa etapa são identificadas classes de conhecimento que podem ser, por exemplo, a área de atuação, atividades-chave, produtos ou serviços, competências-chave ou mesmo quaisquer atividades que agreguem valor à organização. Uma vez identificadas as classes, é preciso então identificar os ativos tangíveis e intangíveis que compõem cada uma delas (EVANS; ALI, 2013).

A segunda etapa consiste nos processos de organizar e armazenar o conhecimento com a finalidade de registrá-lo tornando-o disponível à organização para seu gerenciamento (EVANS; ALI, 2013). Cabe mencionar que a TI desempenha um papel importante nesse processo. Seus avanços têm possibilitado às organizações um controle cada vez mais preciso sobre seus estoques de conhecimento.

O êxito da etapa de compartilhamento é diretamente dependente da etapa anterior e trata dos esforços colaborativos internos, e também externos, no sentido de disponibilizar o conhecimento para melhorar o processo de tomada de decisão individual e coletivo. A comunicação formal e informal é o componente-chave para o compartilhamento (EVANS; ALI, 2013).

A aplicação ou uso do conhecimento é um processo crucial do ciclo da GC. Quando os membros da organização aplicam o conhecimento, eles estão, em outras palavras, desenvolvendo novas perspectivas para lidar com as situações com as quais se deparam. A consequência natural da aplicação do conhecimento proporciona a avaliação, o aprendizado e a criação de novos conhecimentos, dando continuidade ao ciclo (EVANS; ALI, 2013).

Avaliação e aprendizado são processos indissociáveis. A avaliação das atividades desempenhadas pelos membros de uma organização, que ocorre tanto de maneira formal quanto informal, é, por consequência, uma fonte de aprendizado. Ao mesmo tempo, à medida que os 
indivíduos aprendem e ampliam seus conhecimentos, aprimoram sua capacidade avaliativa, tanto de si mesmos quanto dos demais (EVANS; ALI, 2013).

O processo seguinte do ciclo refere-se à criação do conhecimento, que resulta do aprendizado decorrente de experiências passadas, tenham sido bem ou mal sucedidas de acordo com critérios de desempenho estabelecidos. Aqui se tem a dimensão do quão imbricados são todos os processos que compõem o ciclo proposto por Evans e Ali (2013). Essa perspectiva processual da GC evidencia sua natureza holística e complexa, superando possíveis reducionismos que prejudicariam sua compreensão teórica e aplicação prática nas organizações.

Todos esses processos do ciclo de GC estão apoiados por práticas e ferramentas. Kianto e Andreeva (2014, p. 222, tradução nossa) definem práticas de GC como “o conjunto intencional de atividades organizacionais e gerenciais que se destinam a melhorar os processos de conhecimento da empresa". As práticas de GC são descritas na literatura de duas formas. Uma delas é como atividades ou rotinas observáveis relacionadas diretamente à GC (COOMBS; HULL; PELTU,1998; MCKEEN; ZACK ; SINGH, 2006) e nesse sentido as práticas são descritas de modo um pouco mais genérico como identificar as fontes de conhecimento dentro da organização (MCKEEN; ZACK; SINGH, 2006), proporcionar treinamento formal e informal sobre GC, ter uma cultura organizacional que promova o compartilhamento de conhecimento (OECD, 2003), valorizar atitudes e opiniões dos colaboradores (DARROCH, 2003), mapear e entender o conhecimento atual da empresa, integrar iniciativas e planos de GC no planejamento estratégico, formalizar e acompanhar o uso de lições aprendidas (KIANTO; ANDREEVA, 2014), apenas para citar algumas.

A outra forma como as práticas de GC se apresentam na literatura é pela descrição de ações específicas de apoio aos processos do ciclo de GC. No Brasil, a lista mais citada de práticas é a de Batista et al (2005), atualizada posteriormente. As práticas presentes nessa primeira lista foram: fóruns, comunidades de prática, educação corporativa, universidade corporativa, narrativas, mentoring, coaching, melhores práticas, benchmarking interno e externo, memória organizacional também conhecida como lições aprendidas ou banco de conhecimentos -, sistemas de inteligência organizacional, mapeamento ou auditoria do conhecimento, sistema de gestão por competências, banco de competências organizacionais e individuais, gestão do capital intelectual, portais, intranets e extranets, sistemas de workflow, gestão de conteúdo, gestão eletrônica de documentos, data warehouse e data mining.

Nessa categorização de Batista et al (2005) - e também nas versões posteriores desse estudo os autores não diferenciam práticas de ferramentas de GC, elencando ambas como "práticas". Todavia, o conceito de ferramentas de GC está relacionado não às ações ou atividades em si, mas àquilo que dá 
suporte a elas. Ou seja, nessa perspectiva, os portais, intranet e extranet, por exemplo, deveriam ser classificados como ferramentas e não práticas de GC.

Outras questões ainda estão diretamente relacionadas a GC, tais como: cultura organizacional, aprendizagem, comunicação, relacionamentos interpessoais e, inclusive - e talvez até mesmo principalmente - os bens relacionais, que "são aqueles bens que nascem de relacionamentos, de 'encontros' nos quais a identidade e as motivações do outro com o qual se interage são elementos essenciais na criação e no valor do bem" (Gui apud Bruni, 2001). Esses elementos influenciam, inclusive, no nível de satisfação de um trabalhador com relação à sua empresa, podendo até mesmo ser motivadores do desligamento do próprio emprego e da criação de um negócio próprio. Sobre essas motivações trata a próxima seção.

\section{MOTIVAÇÕES EMPREENDEDORAS NA ÁREA DE TECNOLOGIA DA INFORMAÇÃO}

De acordo com a pesquisa Global Entrepreneurship Monitor (GEM 2017), as motivações de se tornar empreendedor podem ser a necessidade ou a oportunidade. Os empreendedores por necessidade decidem empreender por não possuírem melhores alternativas de emprego e renda. Já os empreendedores por oportunidade são capazes de identificar uma chance de negócio ou um nicho de mercado e decidem empreender mesmo possuindo outra alternativa de emprego e renda.

É possível caracterizar o empreendedor por oportunidade como um indivíduo movido pela busca da autonomia pessoal e que está atento às oportunidades. Além disso, o próprio apreço por um produto ou serviço pode levar um indivíduo a empreender, se houver uma condição favorável de negócio:

Entre os principais motivos que impulsionam o indivíduo a agir, situa-se a necessidade de conquistas e realizações. Ou seja, um desejo de realizar as coisas da melhor maneira, não exatamente pelo reconhecimento social ou prestígio, mas, sim, pelo sentimento íntimo de necessidade de realização pessoal. Indivíduos com elevado nível de necessidade de realização e conquista apresentam maior propensão a perseguir desafios, de maneira relativamente autônoma. (VALE, et al, 2014, p. 315).

Para Antunes (2009), uma vida cheia de sentido fora do trabalho supõe uma vida dotada de sentido dentro do trabalho, ou seja, um indivíduo só poderá se realizar integralmente em todos os âmbitos da sua vida se conseguir ver sentido naquilo que faz durante o trabalho. Pinotti et al (2015) afirma que muitas pessoas iniciam no empreendedorismo pelo desejo de independência e autonomia, que pode ser entendido como liberdade para tomar decisões, distância de processos burocráticos e a busca de liberdade de expressão de suas opiniões. 
Pinho e Thompson (2016) afirmam que os valores culturais e sociais dos indivíduos podem também encorajar ou favorecer ações que conduzam à criação de novos negócios. Para Gimenez (2013), o empreender pode surgir de momentos de frustração na vida do indivíduo, causando um rompimento na vida presente na tentativa de construir um futuro diferente.

No caso específico da área de TI, o empreendedorismo toma formas peculiares. De fato, o setor de tecnologia é dinâmico, com foco em pesquisa e desenvolvimento, relaciona-se diretamente com a inovação de processos, produtos, melhorias nas cadeias produtivas e potencial para desenvolver vantagem competitiva em empresas, por isso é um setor que tem recebido atenção e investimentos em diversos níveis.

Além de empresas de tecnologia tradicionais, surgem também empreendedores que identificam e criam oportunidades no mercado através de inovações e, consequentemente, provocam novas formas de atuação organizacional nos mercados de alta tecnologia, que são as denominadas startups (MIRANDA et al, 2016).

O Sebrae Nacional (2017) define as startups como um modelo de negócios que une um grupo de pessoas que iniciam uma empresa, trabalham com uma ideia diferente, escalável e em condições de extrema incerteza. Ou seja, a finalidade de uma startup, apesar de ser uma ideia que não é completamente segura de sucesso, é crescer em tamanho e faturamento, sem que isso mude seu modelo inicial de negócio.

Ainda que algumas startups já tenham se destacado, no que diz respeito a inovação e aos retornos financeiros gerados, esse é um modelo de negócio que ainda apresenta muita vulnerabilidade inicial, que deve-se ao baixo nível de legitimidade, escassez de recursos e alta dependência de cooperação, gerando uma incapacidade de competir eficazmente com as organizações já estabelecidas. Por outro lado, as startups têm no entusiasmo de seus fundadores a melhor maneira de compensar, mesmo que parcialmente, a vulnerabilidade apresentada.

\section{O SETOR DE TECNOLOGIA DA INFORMAÇÃO NA CIDADE DE MARINGÁ-PR}

A cidade de Maringá vem se consolidando ao longo dos anos como polo da área de TI no Noroeste do Paraná. De acordo com a publicação realizada pelo site de notícias do Jornal Gazeta do Povo, de 2006 até 2016 o crescimento do número de empresas chegou a 69,8\%. Ainda de acordo com a reportagem, a ampliação dos negócios e o bom desempenho do setor se devem à localização estratégica do município, mas principalmente à comunidade acadêmica, que é responsável por grande parte da mão de obra que é absorvida após a conclusão do ensino superior. A reportagem também retrata que os 
softwares desenvolvidos pelas empresas da cidade atendem diversas áreas e segmentos e são comercializados em todo Brasil e alguns até no exterior (FRANCO, 2016).

Em publicação no site de notícias do Jornal Gazeta do Povo (SILVEIRA, 2018), constatou-se que Maringá se destaca nacionalmente no âmbito de empresas do segmento de desenvolvimento de software, visto que a cidade de 400 mil habitantes possui 400 empresas, aproximadamente, nessa área. Outro número significativo, dado o porte da cidade, são os seus 4000 profissionais que atuam nessa área. Maringá é a segunda cidade no país a ter o maior número de empresas com certificações de qualidade em tecnologia - a primeira cidade é São Paulo.

$\mathrm{O}$ setor de tecnologia maringaense também se mostra forte e consolidado quando se trata de faturamento. De acordo com dados apresentados pela Prefeitura de Maringá (SETOR..., 2017), entre os anos de 2012 e 2016 o faturamento saltou de $\mathrm{R} \$ 83,2$ milhões para $\mathrm{R} \$ 603$ milhões. A perspectiva é de um crescimento superior a $60 \%$ até 2020 , superando $\mathrm{R} \$ 1,1$ bilhão. Tamanha robustez do setor tem contribuído para o recebimento de incentivos por parte da prefeitura da cidade, que assinou em março de 2018 um decreto destinando uma área urbana com aproximadamente 120 mil metros quadrados para a implantação do Parque Tecnológico. O objetivo é que o setor se fortaleça ainda mais a partir da reunião, no mesmo espaço físico, de centenas de empresas de TI da cidade, bem como atraia outros atores que compõem o ecossistema de inovação local, como as instituições de ensino superior, pesquisadores, docentes e discentes (ASSINADO..., 2018).

Com os dados de faturamento apresentados e os incentivos oferecidos pela prefeitura, é possível perceber o porquê Maringá está recebendo tantos profissionais qualificados para atuar em empresas de tecnologia e também o motivo desses profissionais se especializarem e se tornarem empreendedores, surgindo com novas ideias, empresas e startups para atuarem nesse mercado na cidade.

\section{PROCEDIMENTOS METODOLÓGICOS}

A pesquisa caracteriza-se como qualitativa e descritiva. A técnica de coleta de dados utilizada foi a de entrevista semiestruturada realizada com seis ex funcionários de empresas privadas da área de TI na cidade de Maringá, que abriram o seu próprio negócio na mesma área.

As entrevistas foram gravadas com autorização prévia de cada entrevistado, transcritas e analisadas por meio de análise de conteúdo, segundo as fases propostas por Bardin (1977): a primeira se refere à organização da análise, suas primeiras hipóteses e intuições, conduzindo a um esquema de desenvolvimento da pesquisa; a segunda fase abrange a análise, ou seja, a administração das decisões 
tomadas; e, por fim, a terceira fase que se refere ao tratamento dos resultados brutos para que se tornem válidos e realmente significativos.

\section{RESULTADOS E DISCUSSÕES}

Para se compreender os elementos que influenciaram a decisão de profissionais da área da TI a empreenderem, é importante entender os fatores que desmotivaram os entrevistados durante o período em que eles atuaram como empregados nas empresas de tecnologia de Maringá. As respostas dos entrevistados foram divididas em três categorias principais: a falta de organização e processos irregulares das empresas, a rotina diária e o salário. A respeito da primeira categoria, dois dos entrevistados citaram pontos falhos das empresas para retenção de pessoas. O entrevistado V citou: “O que mais me incomodava era a falta de organização das empresas, o erro no plano de carreira e, principalmente, o fato de a pessoa ter que saber de tudo e receber um salário baixo". O entrevistado R conseguiu representar de forma clara essa visão:

São dois pontos principais que sempre me incomodaram em todas as empresas que eu passei que são: Em primeiro lugar, não fazer parte das decisões estratégicas sobre o rumo do produto ou projeto, porém, fazer parte do momento da cobrança pela decisão não estar andando conforme 'combinado'. Em segundo lugar, cito as formas de gerenciamento de pessoas e projetos, normalmente muito focado no micro gerenciamento e com práticas de gestão mais inclinadas a empresas com um processo de linha de produção, do que em gestão de capital intelectual.

Em termos de GC, a maioria de seus processos envolve comunicação, interação, apreço pelo compartilhamento de conhecimentos e uso compartilhado do conhecimento organizacional. Observa-se que grande parte desses processos e das práticas que os apoiam está pautada na criação coletiva do conhecimento, o que envolve tanto a participação em decisões estratégicas quanto a escuta e consideração das opiniões e até mesmo da responsabilidade coletiva sobre o trabalho. Ao serem subtraídos das decisões, mas cobrados por resultados insatisfatórios percebe-se que os processos de GC não estavam sendo atuados nessas empresas. A falta de gestão do capital intelectual - exatamente a GC também teve destaque na fala do entrevistado, como fator de desmotivação no trabalho.

Ao tratar sobre a rotina de um trabalho fixo, metade dos entrevistados citou esse aspecto como fator de desmotivação. A esse respeito, o entrevistado T fez a seguinte analogia: "A sensação que eu tinha era que minha vida, de um ponto em diante, seguiria um roteiro que não havia sido escrito por mim: acorda, trabalha, volta para casa, dorme”. Essa característica envolve mais uma vez a questão da 
alienação do funcionário ao conjunto de suas atividades, pois absorvidos por rotinas e não participando de escolhas de projetos ou decisões - características fortes da área de tecnologia - perdiam a motivação e o sentido do próprio trabalho. Essa alienação ficou clara na fala do entrevistado T: "os contras [de ser funcionário em uma empresa de tecnologia], a meu ver, ficam pela dificuldade em enxergar o impacto que o seu trabalho proporciona. Normalmente você é apenas um amontoado de indicadores, às vezes nem sabe se alguém de fato está tendo algum benefício com o que você faz".

Quanto à terceira categoria - a do salário - todos acreditam que deveriam ganhar mais do que recebiam dentro das empresas. O entrevistado V. citou ainda questões mais amplas a esse respeito:

A falta de organização das empresas, o erro no plano de carreira e principalmente o fato de a pessoa ter que saber de tudo e receber um salário baixo. Nunca me conformei com isso, me sentia um peixe fora do aquário tendo o meu futuro decidido por pessoas que nem sabiam ao certo qual era o meu papel dentro da equipe e do projeto.

Essa fala demonstra diversos elementos relacionados à falta de GC nesse tipo de organização. Em primeiro lugar a própria "falta de organização" citada remete a estratégias e processos não claramente definidos. Em seguida, a questão do "erro no plano de carreira", que corrobora a afirmação de outro entrevistado que mencionou sobre seu desejo de ser remunerado por suas entregas. Isso remete a uma prática de GC, que é a gestão por competências.

Segundo essa prática, dentre diversas outras características, os funcionários são remunerados por suas entregas, ou seja, por aquilo que de fato agregam valor à organização a partir de seus conhecimentos, habilidades e atitudes. Esse tipo de gestão se demonstra adequado ao setor de tecnologia, dado que esse o reconhecimento de suas entregas é um dos anseios dos profissionais dessa área. A afirmação de "tendo meu futuro decidido por pessoas que nem sabiam ao certo qual era o meu papel dentro da equipe e do projeto" indica que os gestores dessas empresas nem sempre têm clareza a respeito das atividades de cada um de seus funcionários e essa premissa é o primeiro aspecto inviabilizador de uma gestão por competências.

Por fim, em diversos momentos das entrevistas emergiram questões de desmotivação no trabalho por falta de elementos que compõem a GC - algo tão fundamental para a área de TI. Desse modo, a necessidade de atuar profissionalmente em um ambiente em que houvesse uma efetiva GC tornou-se propulsora da decisão desses entrevistados empreenderem na área de TI.

\section{CONSIDERAÇÕES FINAIS}


Ao buscar compreender a influência da GC na motivação empreendedora de profissionais da área de TI, diversas questões emergiram. Primeiramente a necessidade da práxis da GC em empresas de TI, por se tratar de uma área intensiva em conhecimento e permeada por processos interligados entre si.

Outra questão foi a verificação de que a ausência dessa práxis gerou descontentamento e desmotivação nos funcionários dessa área. Fatores como a não participação na criação do conhecimento nem no seu uso, a falta de compartilhamento do conhecimento - tanto por parte dos gestores estratégicos quanto por parte dos funcionários, por não serem a eles solicitado esse compartilhamento - e a consequente alienação ao resultado do próprio trabalho influenciaram diretamente funcionários da área de TI a deixarem seus empregos e a decidirem empreender, abrindo um negócio próprio, no qual pudessem agir de modo coerente com seus valores, crenças e até mesmo modelo organizacional almejado.

Somam-se a isso, questões relacionadas à política salarial das empresas de TI nas quais trabalhavam os entrevistados que não condiziam com uma prática voltada a entregas e resultados efetivos, mas que se pautavam em cumprimento de horários rígidos e tetos salariais. A prática de gestão por competências se mostrou nesse caso como inexistente nessas empresas, mas necessária para a motivação de profissionais dessa área, voltados a processos criativos e inovadores.

Por fim, pode-se concluir que esses profissionais da área de TI, embora talvez não tivessem consciência de que almejassem a vivência da GC nas empresas em que trabalhavam, sentiam como sendo questões críticas as ações que indicavam exatamente a falta dessa gestão, de seus processos, suas práticas e ferramentas. De fato, os dados obtidos na pesquisa evidenciaram a necessidade desses profissionais de terem um maior domínio e se apropriarem também de toda a construção dos repertórios de conhecimento das organizações das quais faziam parte e na aparente impossibilidade de que isso pudesse acontecer nas empresas em que trabalhavam, se sentiram motivados a deixar esses empregos e a empreender na área de TI, criando assim um modelo de negócio e de gestão condizente com o que acreditavam e pautado, mesmo que de forma não formalizada, na GC e seus elementos. 


\section{REFERÊNCIAS}

ANTUNES, R. Os sentidos do trabalho: Ensaio sobre afirmação e a negação do trabalho. São Paulo: Boitempo, 2009. 292p.

ASSINADO decreto que destina terreno para Parque Tecnológico. Maringá: Prefeitura de Maringá. 2018. Disponível em: <http://www2.maringa.pr.gov.br/site/index.php ?sessao=9833621b675598\&id=32642 >.

Acesso em: 01 Ago2018.

BARDIN, L. Análise de Conteúdo. São Paulo: Livraria Martins Fontes, 1977. 229p.

BATISTA, F. F.; QUANDT, C. O.; PACHECO, F. F.; TERRA, J. C. C. Gestão do Conhecimento na administração pública. Texto para discussão n. 1095. Instituto de Pesquisa Econômica Aplicada. Ministério do Planejamento, Orçamento e Gestão, 2005.

BERGER, P. L.; LUCKMANN, T. A construção social da realidade. 31. ed. Petrópolis: Editora Vozes, 2009. 240p.

BOISOT, M. Knowledge Assets: securing competitive advantage in the information economy. New York: Oxford University Press, 1998. 312p.

BRUNI, L.. L'Economia di Comunione: fatti e idee per un nuovo umanesimo. Congresso Internazionale di Economia, 2001, Castelgandolfo, 7/04/2001. Disponível em: <http://www.edc-online.org>. Acesso em: 24 out. 2004.

CHOO, C. W. Information management for the intelligent organization: the art of scanning the environment. Medford, New Jersey: Information Today, , 2002. 272 p.

COOMBS, R.; HULL, R.; PELTU, M. Knowledge management practices for innovation: an audit tool for improvement. CRIC, The University of Manchester CRIC Working Paper, n. 6, 1998.

DALKIR, K. Knowledge Management in Theory and Practice. Burlington: Elsevier,2011. 368p.

DARROCH, J. Developing a measure of knowledge management behaviors and practices. Journal of Knowledge Management, v. 7, n. 5, p. 41-54, dez. 2003.

DAVENPORT, T. H.; PRUSAK, L. Conhecimento empresarial: como as organizações gerenciam o seu capital intelectual. Rio de Janeiro: Elsevier, 2003.

DRUCKER, P. F. Uma era de descontinuidade: orientações para uma sociedade em mudança. 3.ed. Rio de Janeiro:Zahar Editores, 1976. 427p.

EVANS, M. M.; ALI, Natasha. Bridging knowledge management life cycle theory and practice. In: International Conference on Intellectual Capital, Knowledge Management and Organisational Learning ICICKM 2013Conference Proceedings... 2013. p. 156-165.

FRANCO, G. Maringá se firma como polo regional em Tecnologia da Informação. Gazeta do Povo, Maringá, PR, 2016. Disponível em: <http://www.gazetadopovo.com.br/economia/m aringa-se-firma-como-polo-regional-emtecnologia-da-informacao0feri4nke7v81w8s3qak8hrl6>. Acesso em 01 mai. 2018.

GEM- Global Entrepreneurship Monitor. Empreendedorismo no Brasil.:2016. Curitiba: IBQP, 2017. 208p.

GIMENEZ, F. A. P. Empreendedorismo e pequena empresa: Dezesseis Haikais, um pouco de prosa e outros versos. Curitiba: Edição do Autor, 2013.106p.

HANSEN, M. T.; NOHRIA, N.; TIERNEY, T. What's your strategy for managing knowledge. The knowledge management yearbook 2000-2001, v. 77, n. 2, p. 106-116, 1999.

KIANTO, A.; ANDREEVA, T. Knowledge Management Practices and Results in ServiceOriented versus Product-Oriented Companies. Knowledge and Process Management, v. 21, n. 4, p. 221-230, ago. 2014.

KUHN, Thomas S. A estrutura das revoluções científicas. 6. ed. São Paulo : Perspectiva, 2001. 324p.

LEMOS, A.H.C. da. et al. De empregado a empresário: Mudanças no sentido do trabalho para empreendedores. Revista Pensamento Contemporâneo em Administração, v.11, n. 5, p. 103-115, out./dez. 2017.

MCKEEN, J. D.; ZACK, M. H.; SINGH, S. Knowledge management and oanizational performance: An exploratory survey. In: ANNUAL HAWAII INTERNATIONAL CONFERENCE ON SYSTEM SCIENCES, 
39, 2006. Proceedings... Kauia: IEEE, 2006. p. $152 \mathrm{~b} 152 \mathrm{~b}$.

MIRANDA, J.Q. et al. A influência das variáveis ambientais e organizacionais no desempenho de startups. Revista de Empreendedorismo e Gestão de Pequenas Empresas, v.5, n.1, 2016.

NONAKA, I.; TAKEUCHI, H. Criação de conhecimento na empresa: como as empresas japonesas geram a dinâmica da inovação. Rio de Janeiro: Elsevier, 1997. 358p.

OECD - Organisation For Economic CoOperation And Development. Measuring knowledge management in the business sector. Paris: OECD Publishing, 2003.

PINHO, J.C; THOMPSON, D. Condições estruturais empreendedoras na criação de novos negócios: A visão de Especialistas. Revista de Administração de Empresas, v.56, n.2, mar./abr. 2016.

PINOTTI, S. et al. Ser ou não ser empreendedor: o profissional técnico e o dilema da mudança de carreira. Revista de Empreendedorismo e Gestão de Pequenas Empresas, v.4, n.3, 2015.

SCOTT, W. R. The Adolescence of Institutional Theory. Administrative Science Quarterly, v. 32, n. 4. p. 493-511, 1987. Disponível em: $<$ http://citeseerx.ist.psu.edu/viewdoc/download ?doi=10.1.1.473.3127\&rep=rep1\&type=pdf $>$. Acesso em: 04 Ago. 2019.

SEBRAE NACIONAL. O que é uma Startup? 2017. Disponível em: < http://www.sebrae.com.br/sites/PortalSebrae/se braeaz/o-que-e-umastartup,616913074c0a3410VgnVCM1000003b 74010aRCRD>. Acesso em 27 mai. 2018.

Recebido em: 20/09/2019

Aceito em: 08/11/2019

Endereço para correspondência:

Nome: Cláudia Herrero Martins Menegassi

Email: claudiaherrero@gmail.com
SETOR de TI projeta crescimento, fomento a inovação e parque. Maringá: Prefeitura de Maringá. 2017. Disponível em: <http://www2.maringa.pr.gov.br/site/index.php ?sessao $=$ be27 da261555be \&id $=31370>$

Acesso em: 01 Ago. 2018.

SILVEIRA, F. Como Maringá se tornou um ótimo destino para os profissionais de tecnologia. Gazeta do Povo, Maringá, PR, 2018. Disponível em: <https://www.gazetadopovo.com.br/economia/li vre-iniciativa/carreira-e-concursos/comomaringa-se-tornou-um-otimo-destino-para-osprofissionais-de-tecnologia6tsrp6x0i9jbop6vv85iwpi2d/>. Acesso em 01 mai 2018.

TAKEUCHI, H.; NONAKA, I. Gestão do Conhecimento. Porto Alegre: Bookman, 2008. 319p.

TARAPANOFF, K. M. A. (Org.). Inteligência organizacional e competitiva. Brasília: Editora Universidade de Brasília, 2001. 344p.

VALE, G..M.V.; CORRÊA, V.S.; REIS, R.F.; Motivação para o empreendedorismo: necessidade versus oportunidade. Revista de Administração Contemporânea, Curitiba, v. 18, número 3, p. 311-327, mai./jun. 2014.

Von KROGH, G.; ROOS, J. A perspective on knowledge: competence and strategy. Personnel Review, v. 24, n.3, p. 56-76, mai. 1995.

WIIG, K. M. Knowledge management foundations: thinking about thinking: how people and organizations create, represent, and use knowledge. Arlington: Schema Press, 1993. 471p.

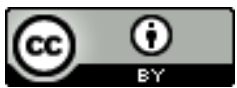

Esta obra está licenciada com uma Licença Creative I Commons Atribuição 4.0 Internacional 